\title{
Relations between daily events, coping strategies and health during a British Army ski expedition across Antarctica
}

\author{
Document Version \\ Accepted author manuscript
}

Link to publication record in Manchester Research Explorer

Citation for published version (APA):

Smith, N., Keatley, D., Sandal, G. M., Kjaegaard, A., Stoten, O., Facer-Childs, J., \& Barrett, E. (2020). Relations between daily events, coping strategies and health during a British Army ski expedition across Antarctica.

Environment \& Behavior.

Published in:

Environment \& Behavior

\section{Citing this paper}

Please note that where the full-text provided on Manchester Research Explorer is the Author Accepted Manuscript or Proof version this may differ from the final Published version. If citing, it is advised that you check and use the publisher's definitive version.

\section{General rights}

Copyright and moral rights for the publications made accessible in the Research Explorer are retained by the authors and/or other copyright owners and it is a condition of accessing publications that users recognise and abide by the legal requirements associated with these rights.

\section{Takedown policy}

If you believe that this document breaches copyright please refer to the University of Manchester's Takedown Procedures [http://man.ac.uk/04Y6Bo] or contact uml.scholarlycommunications@manchester.ac.uk providing relevant details, so we can investigate your claim.

\section{OPEN ACCESS}


1 Relations between daily events, coping strategies and health during a British Army ski expedition across Antarctica

3 Word count: 5934

4

5 Expedition teams operating in Polar environments are exposed to a range of environmental,

6 psychological and social challenges. How a person responds to these demands has

7 implications for their physical and psychological health. In the present study, we examined

8 relations between the daily events encountered, coping strategies used and markers of

9 physical and psychological health in a team of six British Army soldiers (one serving and five reservists) completing a 68-day ski-traverse of the Antarctic continent. In general, daily reports indicated a largely adaptive response to the expedition. There were fluctuations in the events encountered, coping strategies used, and experiences of physical and psychological health throughout the endeavor. Reported daily events and coping strategies explained variability in the positive and negative fluctuations of physical and psychological health. Findings from this study can inform health decision-making of groups operating in Polar environments, and others living and working under similar constraints.

Keywords: daily events, coping strategies, health monitoring, Antarctic expedition, military 
Relations between daily events, coping strategies and health during a British Army ski expedition across Antarctica

Expedition teams operating in Polar environments face a range of physical hazards, including severe temperatures, unrelenting terrain and unpredictable weather. There are also psychosocial challenges. For instance, task demands can result in feelings of monotony and boredom, sleep deprivation, fatigue and fear of injury. Proximity with others and separation from friends and family can lead to feelings of interpersonal stress (Palinkas, 2003; Smith, Kinnafick, \& Saunders, 2017). While some people succumb to these task and environmental demands and experience poor physical and psychological health (Wood et al., 2005), others cope well and derive benefits from their expedition experience (Leon, Sandal, \& Larsen, 2011; Palinkas \& Suedfeld, 2008). Research on these different dynamics of stress, coping and health in Polar settings can be used to understand and ensure the survival, performance and optimal function of other expeditioners, as well as individuals and groups operating under similarly challenging conditions (Smith \& Barrett, 2018; Suedfeld, 2018).

Although researchers have previously examined the physical and psychological function of Polar travelers (e.g., Anton-Solanas, O’Neill, Morris, \& Dunbar, 2016; Blackadder-Weinstein et al., 2019; Gifford et al., 2018; Leon, Sandal, Fink, \& Ciofani, 2011), few studies have explored the situational or day-to-day dynamics that may explain variability in their experience. Studies conducted to date have rarely explored the interrelations between the events encountered, the reaction to those events and the consequent impact upon physical and psychological health (for exceptions, see Kahn \& Leon, 1994 and Leon, Kanfer, Hoffman, \& Dupre, 1991). Knowledge of these relationships is crucial for monitoring purposes, understanding when health might be at risk and for recommending strategies to facilitate coping and optimize individual (and team) function. In the present study, we address this gap in the literature by examining the relations between the daily events 
encountered, coping strategies used and experiences of physical and psychological health in a team of British Army soldiers completing an unassisted ski expedition across the Antarctic continent.

The safe and successful completion of a Polar ski expedition is more likely when individuals maintain a healthy physical and psychological state. This means staying physically fit, by avoiding injuries and ensuring appropriate calorific intake, and regularly experiencing positive mood and emotions (Palinkas \& Suedfeld, 2008). Studies of Polar expedition teams suggest that in general individuals do tend to maintain good levels of physical and psychological health (Atlis, Leon, Sandal, \& Infante, 2004; Blackadder-

Weinstein et al., 2019; Gifford et al., 2018; Leon, Sandal, Fink et a., 2011). Weekly ratings of positive affect, for instance, tend to be scored higher than negative affect across time spent in the field (see Leon, Sandal, \& Larsen, 2011). Collectively, existing findings suggest a degree of stability in Polar expeditioners' physical and psychological health. However, recent evidence indicates that the stability observed in week-by-week or month-by-month measurements may mask changes that occur at a more granular level (e.g., day-to-day; Smith, 2018). These changes may be affected by daily experiences such as getting injured, feeling fatigued or lacking sleep (Anton-Solanas et al., 2016; Smith, Barrett, \& Sandal, 2018). To effectively support expeditioners, further research is needed to understand the situational health changes they experience and the events that precede them.

In the past, diaries (e.g., Suedfeld, Shiozaki, Archdekin, Sandhu, \& Wood, 2017) and weekly reports (e.g., Leon, Sandal, Fink et al., 2011) from Polar expeditioners have provided valuable data on expedition experiences. Expeditioners commonly highlight rewarding aspects of their journeys, including enjoying the Polar environment (Atlis et al., 2004), feeling a sense of camaraderie with team mates (Kjaergaard, Leon, \& Fink, 2015), feeling able to cope (Leon, Sandal, Fink et al., 2011b) and taking satisfaction from making progress 
towards goals (Atlis et al., 2004). Such positive experiences are likely to stimulate more positive emotions, foster team cohesion, engender a sense of control and build confidence, thereby contributing to the safe and successful achievement of expedition goals (Suedfeld, 2001).

Despite expeditions often being marked by positive features, Polar expeditioners have also referred to experiencing a range of harmful and threatening incidents during their travels. This includes injuries and illnesses (Leon \& Venables, 2015), poor weather conditions (Smith et al., 2017), equipment loss and malfunction (Suedfeld et al., 2017) and experiencing tension with teammates (Blackadder-Weinstein et al., 2019). Such negative events have been associated with decrements in performance and health, including impaired decision-making (Atlis et al., 2004), interpersonal conflict (Corneliussen, Leon, Kjærgaard, Fink, \& Venables, 2017) and irritation and mood disruption (Leon, Sandal, Fink et al., 2011; Suedfeld et al., 2017). It is these events, and associated health impacts, that may signal acute periods of risk. If not effectively dealt with, such events could lead to mistakes and the eventual abortion of an expedition or mission, or more serious consequences such as injury or death (Leon \& Venables, 2015).

How a person adjusts and copes with the challenges posed by the Polar environment has been linked to a range of individual difference factors, such as personality, habitual coping approaches and a person's current health status (Leon, 1991; Leon, Sandal, \& Larsen, 2011; Sandal, Leon, \& Palinkas, 2006; Sandal \& Smith, 2017). In general, personality traits linked to effective coping in Polar contexts include being higher than average on measures of conscientiousness, agreeableness and openness, and being emotionally stable (Kjaergaard et al., 2015; Leon, Sandal, \& Larsen, 2011; Palinkas \& Suedfeld, 2008). Habitual coping approaches, including active problem-solving and using comforting self-talk, are broadly considered to be adaptive for coping with extreme stress (Leon, Sandal, \& Larsen, 2011). 
98

99

100

101

102

103

104

105

106

107

Good pre-departure emotional health, characterized by high levels of positive affect, is also likely to be protective of health when entering extreme settings (Maguen et al., 2008; Wagstaff \& Leach, 2015). While it remains important to examine how individual differences affect adjustment and adaptation to extremes, dynamic factors such as the strategies that individuals use to cope during an expedition are likely to be an immediate determinant of their physical and psychological health (Palinkas \& Suedfeld, 2008; Smith et al., 2018).

Coping strategies can be conceived of as either problem-focused or emotion-focused (Lazarus and Folkman, 1984). Problem-focused strategies aim to resolve a stressful encounter directly, whereas emotion-focused strategies are mobilized when a person appraises that nothing can be done to change the situation. Common problem-focused strategies used by Polar expeditioners include actively solving problems as they occur (Suedfeld et al., 2017) and engaging in more effortful behavior (Blackadder-Weinstein et al., 2019). Emotionfocused methods that are regularly endorsed include trying to relax (Leon, Sandal, Fink et al., 2011b), emotion suppression (Wagstaff \& Weston, 2014), sharing concerns and seeking support (Blackadder-Weinstein et al., 2019; Devonport, Lane, \& Lloyd, 2011), viewing the situation in a positive way (Kjaergaard et al., 2015) and relying on humor (Corneliussen et al., 2017).

Though there have been numerous studies on coping in Polar contexts, few have focused on the situational determinants of the strategies that individuals use to regulate their daily experience (Leon et al., 1991; Smith et al., 2017). Our understanding of the links between the daily use of coping strategies at the point when a demand is faced and indicators of physical and psychological health during Polar expeditions is thus limited. Results from a study with an Antarctic mountaineering expedition team suggest that certain strategies, such as positive reappraisal, may be effective for regulating the psychological experience (Wagstaff \& Weston, 2014). However, there is likely to be significant intra- and inter- 
individual variability in how people cope. Indeed, other Polar researchers have suggested that regulatory flexibility (the capacity to select the most appropriate coping strategies based on the demand(s) faced; Bonnano \& Burton, 2013) is likely to be needed to maintain performance and health and to deal with the changing situational demands in these extreme and unpredictable settings (Kjaergaard et al., 2015). Examining relationships between daily coping strategies and physical and psychological health, while accounting for person-level variations, will provide a more nuanced understanding of coping in these hazardous, unremitting environments.

The overall aim of the current study was to examine the daily events encountered, coping strategies used and markers of physical and psychological health during a Polar ski expedition across the Antarctic continent. Primarily, we were interested in how daily events and coping strategies impacted upon physical and psychological health. A secondary aim was to explore how expeditioners adjusted to the environment and how the reported events and coping strategies used changed over time.

\section{The Expedition}

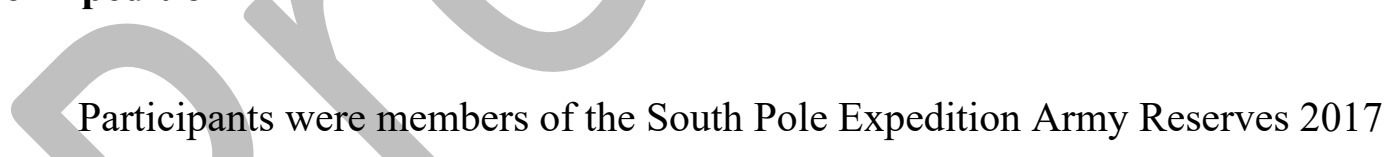

(SPEAR17) expedition, an unassisted ski journey from Antarctica's Hercules Inlet to the Ross Ice Shelf via the South Pole (approximately 1100 miles). During the expedition, the team averaged 14.42 nautical miles $($ Range $=0-19.10 \mathrm{~nm})$ and 9.16 hours skiing $($ Range $=0$ -11 hours) each day. On five days the team made no progress: because of illness (day 32), taking on new supplies at the South Pole (days 41-43) and bad weather (day 62). At the South Pole the team completed a dynamic risk assessment resulting in one team member 
146

147

withdrawing from the expedition due to health concerns. The five remaining team members continued, arriving at their final location and being picked up from the ice after 68 days.

\section{Participants}

The SPEAR17 team included six male members of the British Army (age range $26-$ 47 years; $M d n=32$ years). The expedition leader was a career soldier with over 20 years of service. The others were Army reservists: three medical doctors, a paramedic and a web developer. All had experience of operating in challenging and demanding environments but had varying degrees of expedition experience and exposure to Polar settings. The expedition leader had previously completed a self-supported Polar ski expedition. Other team members had participated in expeditions (ocean rowing) and endurance activities (ultramarathons) in remote environments but had no previous experience of Polar ski expeditions.

\section{Procedure \\ Procedure}

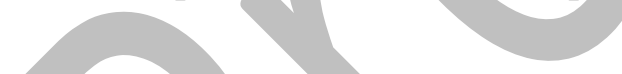

After institutional ethical approval, we provided members of the expedition with information on the nature and purpose of the study. Given the small number of participants, the unique route followed and the expedition's international profile, it was unrealistic to conceal the identity of the expedition team. Therefore, as part of the research consent process, expeditioners were asked to confirm that we could name the expedition under the proviso that individual identities would be protected. All participants provided signed consent.

Approximately six weeks prior to leaving the UK for Antarctica, the first author visited the team at one of their training camps and administered a multi-section pre-departure questionnaire. As part of this pre-expedition meeting the team members were also briefed on how to complete the structured daily diary that would be used to collect data during the expedition. Once the expedition had started, team members were asked to complete one diary entry at the end of each expedition day. 
170

171

Measures

\section{Pre-expedition questionnaire.}

Personality. Personality was assessed using the Big Five Inventory (BFI; John,

Donahue \& Kentle, 1991). Expeditioners responded to 44 items tapping into five subscales of personality: Conscientiousness (nine items; e.g., "does a thorough job”), Agreeableness (nine items; e.g., "is helpful and unselfish with others"), Openness (ten items; e.g., "has an active imagination"), Extraversion (eight items; e.g., "is talkative") and Neuroticism (eight items; e.g., "worries a lot"). Participants were asked about the extent to which each item was like them and responded on a five-point scale ranging from 1 (disagree strongly) to 5 (agree strongly). The psychometric properties of the BFI have been evidenced in previous research (Soto \& John, 2009).

Typical coping strategies. Coping strategies were examined using the Utrecht Coping List (UCL; Schreurs, Tellegen, Van der Willige \& Brosshot, 1988). The UCL includes 47 items reflecting seven subscales related to how a person generally copes with stress: Active problem solving (seven items; e.g., "Making a direct intervention when problems occur"), Palliative reactions (eight items; e.g., "Trying to relax"), Avoidance (eight items; e.g., "Giving in, in order to avoid difficult situations"), Social support (six items; e.g., "Sharing one's worries with someone"); Depressive reactions (seven items; e.g., "Isolating oneself totally from other people"), Sharing emotions (three items; e.g., "Showing one's annoyance") and Comforting cognitions (five items; e.g., "Telling oneself that things could be worse"). When responding, participants were asked to think about how they react when confronted with a problem and answer on a four-point scale ranging from 1 (seldom or never) to 4 (very often). The UCL has demonstrated adequate validity and reliability in prior studies (Sandal et al., 2018; Sandal, Endresen, Værnes. \& Ursin, 1999). 
194

195

196

197

198

199

200

201

202

203

204

205

206

207

208

209

210

211

212

213

214

215

216

217

\section{Health and wellbeing.}

Affect. Affect was reported using the Positive and Negative Affect Schedule (PANAS; Watson, Clark \& Tellegen, 1988). The 20-item PANAS includes two subscales (ten items each), one for positive affective states (e.g., interested, enthusiastic) and the other for negative affective states (e.g., upset, scared). When completing the baseline pre-expedition questionnaire, we added the stem "During the past month I have felt..." to each item. Participants responded using a five-point scale ranging from 1 (very slightly or not at all) to 5 (extremely). The PANAS is widely used as a measure of affect and has shown good validity and reliability in many studies (see Crawford \& Henry, 2004).

Wellbeing. We examined pre-expedition well-being using the Subjective Vitality Scale (SVS; Ryan \& Frederick, 1997). The SVS includes seven items that indicate the extent to which a person feels alive and vital (e.g., I have energy and spirt). To each item, we added the stem "In general, in everyday life...". Participants were asked to respond using a sevenpoint scale ranging from 1 (Not at all true) to 7 (Very true). The SVS has shown acceptable psychometric properties when used as a measure of well-being (Bostic, Rubio, \& Hood., 2000).

Mood. The Centre for Epidemiologic Studies Depression Scale-Revised (CESD-R;

Eaton, Muntaner, Smith, Tien, \& Ybarra, 2004) was used as a baseline assessment of mood.

The CESD-R includes 20 items targeting nine different depression symptom groups (e.g., Concentrating - "I had trouble keeping my mind on what I was doing"; Sadness - "I felt depressed"). The total CESD-R score is used by clinicians to categorize mood disruption and depression according to varying levels of severity. We added the stem "During the past month..." to each item and participants provided a rating on a four-point scale ranging from 1 (Rarely or none of the time/less than 1 day) to 4 (Most or all the time/5 - 7 days). Scores 
218

219

220

221

lower than 16 suggest there are no clinical issues. Total scores above 16 may indicate signs of mood disruption and mental health difficulties. The CESD-R has been demonstrated as a valid and reliable measure of mood disruption and depression in previous work (Van Dam \& Earleywine, 2011).

Daily experience. Each participant used a structured diary to record their daily experiences during the expedition. The diary included 66 items tapping into perceptions of health and fitness, events experienced and coping strategies used. Diary content was based on a version of the diary used in several published expedition studies (Atlis et al., 2004; Leon, Sandal, Fink et al., 2011; Smith et al., 2018). To minimize their weight, we worked with the team to integrate the rating form into their general-purpose expedition diaries.

Three single-item indicators were used to rate physical and psychological aspects of health: scaled questions on fitness (i.e., how physically fit you feel), exertion (i.e., how hard you are working) and perceived stress (i.e., current level of stress). Daily affect, assessed via the 20-item PANAS, was used as the primary measure of psychological health. The occurrence of positive and negative experiences during the day was recorded on a 24 -item rating checklist. A 19-item coping strategy checklist, derived from work with military personnel (Ben-Porath, Leon, Rinehart, Gupton, \& Sineps, 1991), was used to examine the methods team members used to cope.

The diaries took approximately five minutes to complete at the end of each expedition day. We received completed daily diaries from five of the six team members. We did not receive a diary from the team member who had to withdraw from the expedition and his daily reports are not included in our analysis.

\section{Data analysis}


Although consent was provided to name the expedition being studied, we have taken

242 measures to protect individual participants' identities. Data is presented at the team level to ensure anonymity but range and standard deviation scores are meaningful and indicative of team member individual differences.

Descriptive statistics (Mean, SD, Range, Min., and Max.) were computed for all questionnaire subscales and the three single-item indicators (fitness, exertion, stress) in the daily diary. The resulting values were used to create a pre-expedition profile and to examine day-to-day fluctuations in and interrelations between expeditioners' reports of health. Responses to the event and coping checklists were treated as categorical (e.g., event encountered yes $=1$ or no $=0$ ). Separately, each of the events encountered and coping strategies reported during the expedition were summed to create an overall frequency rating. A series of linear mixed models (LMMs) were tested to examine the interrelations between fluctuations in the daily events reported, coping strategies used and indicators of physical and psychological health (fitness, exertion, affect and stress). We considered LMMs the most appropriate form of analysis given the nested data structure (311 daily diary entries nested within 5 participants). This approach allowed us to examine interrelations between variables while controlling for person-level variability. LMMs have previously been used effectively in other small sample extreme environment studies (e.g., Basner et al., 2014; Smith et al., 2018).

Finally, we used standardized residual scores and chi-square analyses (Clarke \& Crossland, 1985; Keatley, 2018) to examine how the events reported and coping strategies used changed during the expedition and whether these changes were greater or fewer than would be expected by chance alone. Given there was a natural midpoint in the expedition (arriving at the South Pole on day 41), which also coincided with a major event (a team 
265

266

267

268

269

270

271

272

274

275

276

277

278

279

280

281

282

283

284

285

286

287

member leaving the expedition), we used this as an anchor point to contrast the psychological experience in the first and second half of the journey.

\section{Results}

Pre-expedition survey information is presented in Table 1. Expeditioners reported higher scores on conscientiousness and agreeableness, and lower scores on neuroticism when compared to a general population sample (Noftle \& Robins, 2007). Variation was observed in extraversion scores $(\mathrm{Min}=2.50 ; \mathrm{Max}=4.50)$. All team members reported a tendency to use problem-focused techniques and comforting cognitions when dealing with stress. All demonstrated good pre-departure emotional health (positive affect scores higher than negative affect scores), high levels of subjective wellbeing and low mood disruption and depression (scores $<16$ ). One participant had lower positive affect and wellbeing scores and higher mood disruption. This participant reported issues related to sleep difficulties during the assessment period, which is likely to account for their slightly different profile.

Daily diary data suggest that the team members generally maintained good overall physical and psychological health throughout the expedition (see Table 2). Perceived fitness $(M=6.95 ; S D=1.14)$ and exertion $(M=3.98 ; S D=1.03)$ scores were moderate. Positive affect remained high $(M=4.03 ; S D=0.69)$ and negative affect low $(M=1.10 ; S D=0.20)$ across the expedition period. Reports of perceived stress were low on average $(M=0.88 ; S D$ $=1.34)$. Interrelations between daily markers of physical and psychological health are presented in Table 2. Perceptions of fitness were positively correlated with positive affect. Exertion, negative affect and stress were all positively correlated. Fitness was negatively correlated with negative affect and stress and positive affect was negatively correlated with negative affect and stress. 
health are presented in Table 3. Expeditioners regularly reported feelings of being able to cope, camaraderie with teammates, enjoying the environment and satisfaction in making progress. Daily reports of being able to cope, enjoying the environment, making progress and equipment working were associated with feeling physically fit, higher levels of positive affect, lower negative affect and lower reports of stress.

Although recorded less frequently, participants also reported harmful and threatening events including muscle and joint pain, lack of sleep, problems with gear and fear of injury. Muscle and joint pain, fear of injury, loneliness, headaches and tension with teammates were associated with lower reports of fitness, increased ratings of exertion, lower positive affect, higher negative affect and higher stress scores.

The most frequently reported coping strategies and their associations with physical and psychological health are presented in Table 4. Expeditioners regularly reported writing a journal, thinking of something pleasant, keeping the goal in sight, maintaining a positive attitude and using humor and trying to see the situation in a positive way. There were no reported instances of outright arguments, but participants did report having negative feelings about the self and others and having to discuss personal and task concerns. Daily reports of coping strategies, such as trying to have pleasant thoughts and seeing the situation in a positive way, were associated with higher scores of positive affect and lower perceptions of stress. Writing in a journal, prayer, discussing task concerns and having negative feelings about the self were associated with lower ratings of fitness, lower positive affect, higher negative affect and higher perceived stress scores. Reports of relaxing and meditating were linked to lower ratings of negative affect. Trying to take it one day at a time and solve problems were associated with elevated perceptions of stress. 
Daily variability was observed in physical and psychological health during the expedition. A wide range of scores were provided for fitness $($ Range = 7; Min =2; Max =9), which coincided with team member injuries. There was a marked increase in stress and negative affect and decrease in positive affect around day 41, which was when the team reached the South Pole.

Time changes in the events experienced and coping strategies used are reported in Table 5. Lacking privacy, sleep deprivation, muscle and joint pain, concern for teammate wellbeing and concerns over team effectiveness were reported more often than would be expected by chance in the first half and less often than would be expected by chance in the second half of the expedition. In contrast, gear problems, fear of injury and loneliness were reported less than would be expected by chance in the first half and more than would be expected by chance in the second half of the expedition. Alongside these changes, individuals also reported enjoying the environment and being able to cope more often in the second half compared to the first half of the expedition.

Expeditioners reported using task immersion, active problem-solving and discussing personal and task concerns more in the first than second half of the expedition. Individuals were also more likely to report keeping feelings to themselves, having negative feelings about themselves and having negative feelings about others in the first compared to second half of the expedition. In contrast, expeditioners were more likely to report taking the expedition one day at a time in the second compared to first half of the expedition.

\section{Discussion}

The present study focused on events encountered, coping strategies used and experiences of physical and psychological health during a successful military ski-expedition across Antarctica. Findings suggest that team members had a largely positive experience. 
336

337

338

339

340

341

342

343

344

345

346

347

348

349

350

351

352

353

354

355

356

357

358

359

However, daily fluctuations in indicators of both physical and psychological health were observed. These fluctuations were predicted by the daily events encountered and coping strategies used. The withdrawal of one of the team members at the South Pole was a particularly difficult period and resulted in less positive and more negative reports of physical and psychological health. After overcoming this difficulty, the remaining individuals appeared to function well and successfully completed their ski traverse. Study results offer new insight into the situational experience of expeditioners operating in extreme Polar environments and factors that might influence their safety, health and wellbeing.

Pre-expedition profiles suggest that the expeditioners were well-adjusted for adaptation to extreme and stressful settings (Leon, Sandal, Fink et al., 2011; Palinkas \& Suedfeld, 2008; Sandal \& Smith, 2017). The configuration of personality traits (high agreeableness, high conscientiousness and low neuroticism) and typical ways of coping (high active problem-solving, high comforting cognitions) are in keeping with findings of other Polar and extreme environment research (Leon, Sandal, \& Larsen, 2011; Leon, Sandal, Fink et al., 2011; Kjaergaard et al., 2015; Sandal et al., 2006). These individual difference factors are likely to contribute to resilience and protect physical and psychological health when operating under conditions of chronic stress (Lazarus, 1991; Maguen et al., 2008; Sandal et al., 2006).

In common with results from similar Polar expedition studies, we found positive affect generally higher than negative affect across the entire expedition period (BlackadderWeinstein et al., 209; Kjaergaard et al., 2015; Leon, Sandal, Fink et al., 2011). Daily reports of physical and psychological health were correlated (e.g., higher fitness scores were associated with lower reports of negative affect), highlighting the interdependency of the physical and psychological experience. Variability observed in expeditioners' daily reports of 
360

361

362

363

364

365

366

367

368

369

370

371

372

374

375

376

377

378

379

380

381

382

health underlines the value of day-to-day monitoring of people in extreme settings (Smith et al., 2018).

\section{Daily events and physical and psychological health}

Reported positive experiences (e.g., enjoying the environment, feeling able to cope and taking satisfaction from progress) were associated with more adaptive physical and psychological health responses. In extreme Polar environments, nourishment of physical and psychological health is likely to help individuals and teams maintain their performance under conditions of chronic stress (Driskell, Salas, \& Driskell, 2018; Wagstaff \& Leach, 2015). The pattern of relationships observed in the present study may be explained by theories of human motivation. For example, self-determination theory (SDT; Deci \& Ryan, 2000; Vansteenkiste \& Ryan, 2013) suggests that individuals will function optimally and experience better health when their basic psychological needs for autonomy, competence and relatedness are met.

Being able to cope and taking satisfaction from making progress should generate feelings of autonomy and competence, which, according to SDT, would then result in adaptive health responses (Goemaere, Vansteenkiste, \& Van Petegen, 2016).

As expected, negative experiences, even those rated infrequently, had an adverse impact upon health and wellbeing. This is consistent with previous research that suggests diverse negative experiences are likely to have a greater impact upon group dynamics, performance and health than positive experiences, despite the latter being more common (Wagstaff \& Weston, 2014; Wood, Hysong, Lugg, \& Harm, 2000). In particular, reports of loneliness predicted multiple negative health responses, suggesting that isolation and separation from established social networks in expedition environments (even when part of a cohesive expedition team) can have a damaging impact on health (Smith \& Barrett, 2018). 
In contrast to positive events, negative events are more likely to thwart an individual's

basic psychological needs for autonomy, competence and relatedness (Goemaere et al., 2016; Vansteenkiste \& Ryan, 2013). Loneliness, for instance, is likely to thwart a person's sense of relatedness. While, muscle and joint pain is likely to impair task performance and hinder progress, thereby frustrating autonomy and competence. The frustration of the psychological needs has recently been linked to a range of adverse health responses in isolated and extreme teams and may explain the health impact of negative events in the present work (Goemaere et al., 2016). Interestingly, individuals who were not experiencing pain but were nevertheless concerned about the effectiveness of teammates might have experienced an increased sense of competence because of taking on additional responsibility (in the present case, taking weight from another team member's pulk) and therefore having an increased status within the team. This may explain why concerns for teammate wellbeing were associated with higher perceptions of fitness.

\section{Coping strategies and physical and psychological health}

\section{Bonnano and Burton (2013) suggest that how a person copes will depend on the} context, the repertoire of strategies they have available and whether these strategies are, or have previously been, effective for mitigating experiences of stress. In the present study, writing a journal was the most frequently reported coping strategy used by team members. Journal-keeping on Polar expeditions has a long history (Mocellin \& Suedfeld, 1991).

Creating a narrative of the experience, documenting important milestones and encounters and recording private thoughts about the expedition is likely to serve multiple coping functions, offering an outlet to vent frustration and fill time during periods of low activity. Participants also reported emotion-focused coping strategies, such as focusing on positive thoughts, keeping a positive attitude, using humor and trying to see the situation in a positive way. Such approaches are likely to help individuals deal with persistent and largely uncontrollable 
408

409

410

411

412

413

414

415

416

417

418

420

421

422

423

424

425

426

427

428

429

430

431

issues (e.g., lack of sleep, muscle pain) faced in Polar settings (Kjaergaard et al., 2015; Leon, Sandal, \& Larsen, 2011). Avoidance coping approaches (e.g., keeping feelings to self) may help avoid arguments and minimize tension in small interdependent expedition teams (Corneliussen et al., 2017; Smith et al., 2017; Wagstaff \& Weston, 2014). However, overreliance on avoidance strategies could potentially result in less functional communication and cooperation between members of a team and have an overall adverse impact on team performance (Sandal et al., 2006).

Pleasant thoughts and seeing the situation in a positive way were associated with higher positive affect scores. Such emotion-focused strategies help people identify the enjoyable and satisfying aspects of an experience by distracting them from unpleasant features and re-focusing attention on areas that are more agreeable (Folkman \& Morowitz, 2004). Techniques including writing a journal, prayer, active problem solving and discussing concerns were associated with less adaptive health responses, including lower fitness, lower positive affect and higher stress scores. Coping approaches such as problem-solving and discussing task and personal concerns may be mobilized in response to specific stressful events, which may explain these associations.

\section{Time-based changes}

A notable example of the temporal changes in events, coping and health is the marked increase in negative affect and perceived stress and reduction in positive affect upon reaching and after leaving the South Pole. The expedition leader decided that a team member who was struggling with his physical health should not continue beyond the South Pole. This meant that the team had to carry on without one of their comrades. The change in health reports at this time may reflect this loss as well as the reality of facing several more weeks of physical effort and isolation with a diminished team. During this difficult period, team members 
432

433

434

435

436

437

439

440

441

442

443

444

445

446

447

tended to rely on emotion-focused techniques, including summoning up pleasant thoughts, trying to keep the goal in sight, maintaining a positive attitude and seeing the situation in a positive way. The expedition leader, who was responsible for the safety of the group, also reported using problem-solving strategies, discussing task concerns and keeping feelings to himself. These techniques may have helped him explain and rationalize his decision to withdraw the struggling team member.

In the second half of the expedition participants generally reported fewer concerns, suggesting that the team actually became more comfortable with the task and environmental demands (Sandal, Bergan, Warncke, Værnes, \& Ursin, 1996; Smith et al., 2018). Changes in the type of events and coping strategies reported may also reflect the team becoming more functional after the withdrawal of the struggling team member. Negative events commonly reported later in the expedition included having problems with gear, which was starting to break due to overuse, and fearing injury, maybe due to fatigue and prolonged exertion. Reports of loneliness increased, although reports of camaraderie with teammates also rose from the first to the second half of the trip, indicating that loneliness may be more likely to be caused by separation from friends and family than by issues within the expedition team.

\section{Our results emphasize coping as a dynamic process. Early in the expedition, as the} team was adjusting to the environment, individuals were more likely to cope by restricting their emotional sharing and by using more active strategies, such as task immersion, active problem solving and putting in more effort. Restricting emotional sharing, particularly during the early phases of an expedition, may be due to concerns about over-burdening teammates, which has previously been observed in other isolated Polar groups (Leon, Sandal, \& Larsen, 2011). After adjusting to the environment, reliance on active problem-focused coping approaches reduced. In the second half of the expedition, individuals used more positively framed emotion-focused techniques, for instance, 'trying to see the situation in a positive 
457 way', 'taking it one day at a time' and 'keeping the goal in sight'. Such approaches help

458 motivate people towards their goals and foster a sense of control and competence by

459 providing small but regularly achievable targets, which should help maintain a sense of

460 purpose during long, repetitive and arduous expeditions (Smith et al., 2017).

\section{$461 \quad$ Limitations}

Daily data from the individual who withdrew from the expedition at the South Pole was not available for analysis. Their data, particularly their reports of events and use of coping strategies, would have added to our understanding of the psychosocial processes of interest to the present work. Although difficult to study in situ, the psychosocial factors underpinning individual and team failures in extreme expedition settings warrant further attention (Leon \& Venables, 2015).

Small sample sizes are common in the extreme environment literature and remain a challenge, including in the present study. We made efforts to address this by adopting an intensive sampling procedure. Although repetitive sampling can sometimes lead to response fatigue, the daily variability we observed in the expeditioner scores suggest that this was not an issue in our study. Nevertheless, the small number of participants does necessitate caution when considering the generalizability of these findings to other individuals and groups operating in extreme settings.

From a conceptual and methodological perspective, we still need to unpack the antecedents and outcomes of daily expedition events and coping strategies. The question stem we used for the event and coping checklists ("identify the events you experienced during the day/identify the methods you used to cope during the day") was worded in a way that meant responses logically preceded reports of physical and psychological health ("how do you feel right now?"). However, because the diary was completed at only one time-point and 
481

responses to all items were provided concurrently (i.e., events and coping were reported at the same time as health), we cannot be certain of the direction of the observed relationships. Separating reports of events and coping strategies from the end-of-day reports of health, perhaps by collecting responses at several points throughout an expedition day, would help to determine the role of events and coping strategies as antecedents of health. Asking expeditioners to report on their perceptions of the effectiveness of coping strategies used would advance our understanding of regulatory flexibility and the dynamic nature of effective coping in extreme settings (Bonnano \& Burton, 2013).

\section{Implications for practice}

If certain events and coping strategies contribute to more positive physical and psychological health responses, finding ways to promote or train these methods could contribute to expeditioner resilience (Maguen et al., 2008; Tice, Baumeister, Shmueli, \& Muraven, 2007). Findings might also inform dynamic risk assessments in the field. For instance, if an expedition leader is aware of how a person is likely to react following certain daily events, and the health responses that accompany their selected coping methods, they might choose to reassign tasks, adjust individual and team goals, make efforts to optimize team interactions, or, in the worst case, call for help.

\section{Conclusions}

The present study extends prior work by offering a more contextualized view of the expedition experience. Specifically, we identify relations between daily events encountered, coping strategies used and their links to physical and psychological health in an extreme expedition context. Understanding daily experiences is critical to providing effective support and informing the design of appropriate health countermeasures for individuals and teams operating in environmental extremes. 
505

506

507

508

509

510

511

512

513

514

515

516

517

518

519

520

521

522

523

524

525

526

References

Anton-Solanas, A., O’Neill, B. V., Morris, T. E., \& Dunbar, J. (2016). Physiological and Cognitive Responses to an Antarctic Expedition: A Case Report. International Journal of Sports Physiology and Performance, 11, 1053-1059. http://dx.doi.org/10.1123/ijspp.2015-0611

Atlis M. M., Leon G. R., Sandal G. M., \& Infante M. (2004). Decision processes and interactions during a two-woman traverse of Antarctica. Environment and Behavior, 36, 402-423. https://doi.org/10.1177/0013916503262217

Barnes, C. M., \& Hollenbeck, J. R. (2009). Sleep deprivation and decision-making teams: Burning the midnight oil or playing with fire? Academy of Management Review, 34, 5666.

Basner, M., Dinges, D. F., Mollicone, D. J., Savelev, I., Ecker, A. J., Di Antonio, A.,...Sutton, J. P. (2014). Psychological and behavioral changes during confinement in a 520-day simulated interplanetary mission to mars. PLoS ONE, 9. doi: 10.1371/journal.pone.0093298

Blackadder-Weinstein, J., Leon, G. R., Norris, R. C., Venables, N. C., \& Smith, M. (2018). Individual Attributes, Values, and Goals of an All-Military Women Antarctic Expedition. Aerospace Medicine and Human Performance, 90, 18-25. DOI: https://doi.org/10.3357/AMHP.5248.2019

Ben-Porath, Y., Leon, G. R., Rinehart, J., Gupton, H., \& Sineps, M. (1991). Variation and covariation among personality, stress, coping, and mood. Paper presented at the 99th Annual Meeting of the American Psychological Association, San Francisco, California. 
527 Bonanno, G. A., \& Burton, C. L. (2013). Regulatory Flexibility: An Individual Differences Perspective on Coping and Emotion Regulation. Perspectives on Psychological Science, 8, 591-612. https://doi.org/10.1177/1745691613504116

530

Bostic, T. J., Rubio, D. M., \& Hood, M. (2000). A validation of the Subjective Vitality Scale using structural equation modelling. Social Indicators Research, 52, 313- 324. doi:10.1023/A:1007136110218

Clarke, D. D., \& Crossland, J. (1985). Action systems: An introduction to the analysis of complex behaviour. London: Methuen

Corneliussen, J. G., Leon, G. R., Kjærgaard, A., Fink, B. A., \& Venables, N. C. (2017). Individual Traits, Personal Values, and Conflict Resolution in an Isolated, Confined, Extreme Environment. Aerospace Medicine and Human Performance, 88, 535-543. doi: 10.3357/AMHP.4785.2017

Crawford, J. R., \& Henry, J. D. (2004). The Positive and Negative Affect Schedule (PANAS): Construct validity, measurement properties and normative data in a large non-clinical sample. British Journal of Clinical Psychology, 43, 245-265. https://doi.org/10.1348/0144665031752934

Deci, E. L., \& Ryan, R. M. (2000). The "what" and "why" of goal pursuits: Human needs and the self-determination of behavior. Psychological Inquiry, 11, 227-268. doi:10.1207/S15327965PLI1104_01

Devonport, T., Lane, A. M., \& Lloyd, J. (2011). Keeping Your Cool: A Case Study of a Female Explorer's Solo North Pole Expedition. Wilderness \& Environmental Medicine, 22, 333-337. doi: 10.1016/j.wem.2011.07.003 
549

550

551

552

553

554

555

556

557

558

559

560

561

562

563

564

565

566

567

568

569

570

571

Driskell, T., Salas, E., \& Driskell, J. E. (2018). Teams in extreme environments: Alterations in team development and teamwork. Human Resource Management Review, 28, 434449. https://doi.org/10.1016/j.hrmr.2017.01.002

Eaton W. W, Muntaner C, Smith C, Tien A, Ybarra M. (2004). Center for Epidemiologic Studies Depression Scale: Review and revision (CESD and CESD-R). In: Maruish ME, ed. The Use of Psychological Testing for Treatment Planning and Outcomes Assessment. 3rd ed. Mahwah, NJ: Lawrence Erlbaum; 363-377

Folkman, S., \& Moskowitz, J. T. (2004). Coping: Pitfalls and promise. Annual Review of Psychology, 55, 745-774. DOI: 10.1146/annurev.psych.55.090902.141456

Fletcher, D., and Sarkar, M. (2013). Psychological Resilience. European Psychologist, 18, 12-23. doi: 10.1027/1016-9040/a000124

Gifford, R. M., O'Leary, T., Cobb, R., Blackadder-Weinstein, J., Double, R., Wardle S. L., ...Woods, D. R. (2018). Female Reproductive, Adrenal, and Metabolic Changes during an Antarctic Traverse. Medicine \& Science in Sports \& Exercise, 51, 556-567. DOI: 10.1249/MSS.0000000000001803

Gloria, C. T., \& Steinhardt, M. A. (2016). Relationships Among Positive Emotions, Coping, Resilience and Mental Health. Stress \& Health, 32, 145-156. DOI: 10.1002/smi.2589

Goemaere, S., Vansteenkiste, m., \& Van Petegem, S. (2016). Gaining deeper insight into the psychological challenges of human spaceflight: The role of motivational dynamics. Acta Astronautica, 121, 130-143. https://doi.org/10.1016/j.actaastro.2015.12.055

John, O. P., Donahue, E. M., \& Kentle, R. L. (1991). The Big Five Inventory Versions 4a and 54. Berkeley: University of California, Berkeley, Institute of Personality and Social Research. 
572

Kahn, P. M., \& Leon, G. R. (1994). Group climate and individual functioning in an allwomen Antarctic expedition team. Environment and Behavior, 26, 669-97. https://doi.org/10.1177/0013916594265004

Keatley, D. A. (2018). Pathways in crime: an introduction to Behaviour Sequence Analysis. London: Palgrave McMillan.

Kjaergaard, A., Leon, G. R., \& Fink, B. A. (2015). Personal Challenges, Communication Processes, and Team Effectiveness in Military Special Patrol Teams Operating in a Polar Environment. Environment and Behavior, 47, 644-666. https://doi.org/10.1177/0013916513512834

Lazarus, R. S. (1991). Emotion and adaptation. New York: Oxford University Press.

Lazarus, R. S., \& Folkman, S. (1984). Stress, appraisal and coping. New York: Springer.

Leon, G. R. (1991). Individual and group process characteristics of polar expedition teams. Environment and Behavior, 23, 723-748. https://doi.org/10.1177/0013916591236005

Leon, G. R., \& Venables, N. C. (2015). Fearless Temperament and Overconfidence in an Unsuccessful Special Forces Polar Expedition. Aerospace Medicine and Human Performance 86, 567-570. doi: 10.3357/AMHP.4256.2015

Leon, G. R., Sandal, G. M., \& Larsen, E. (2011). Human performance in polar environments. Journal of Environmental Psychology, 31, 353-360. https://doi.org/10.1016/j.jenvp.2011.08.001

Leon, G. R., Kanfer, R., Hoffman, R. G., \& Dupre, L. (1991). Interrelationships of personality and coping in a challenging extreme situation. Journal of Research in Personality, 25, 357-371. https://doi.org/10.1016/0092-6566(91)90027-N 
594

595

596

597

598

599

600

601

602

603

604

605

606

607

608

609

610

611

612

613

614

Leon, G. R., Sandal, G. M., Fink, B. A., \& Ciofani, P. (2011). Positive experiences and personal growth in a two-man North Pole expedition team. Environment and Behavior, 43, 710-731. https://doi.org/10.1177/0013916510375039

Levine, S., \& Ursin, H. (1991). What is stress? In: Brown, M.R., Koob, G.F., Rivier, C. (Eds.), Stress- Neurobiology and Neuroendocrinology. Marcel Dekker, New York, NY.

Maguen, S., Turcotte, D. M., Peterson, A. L., Dremsa, T. L., Garb, H. N., McNally, R. J., \& Litz, B. T. (2008). Description of risk and resilience factors among military medical personnel before deployment to Iraq. Military Medicine, 173, 1-9.

Mocellin, J. S. P., \& Suedfeld, P. (1991). Voices From The Ice: Diaries of Polar Explorers. Environment \& Behaviour, 23, 704-722.

Noftle, E. E., \& Robins, R. W. (2007). Personality predictors of academic outcomes: Big five correlates of GPA and SAT scores. Journal of Personality and Social Psychology, 93, 116-130. doi:10.1037/0022-3514.93.1.116

Ntoumanis, N., Edmunds, J., \& Duda, J. L. (2009). Understanding the coping process from a self-determination theory perspective. British Journal of Health Psychology, 14, 249260. DOI: $10.1348 / 135910708 X 349352$

Palinkas, L. A. (2003). The psychology of isolated and confined environments: Understanding human behavior in Antarctica. American Psychologist, 58, 353-363. http://dx.doi.org/10.1037/0003-066X.58.5.353

Palinkas, L. A., \& Suedfeld, P. (2008). Psychological effects of polar expeditions. Lancet, 371, 153-163. DOI: https://doi.org/10.1016/S0140-6736(07)61056-3 
615

616

617

618

619

620

621

622

623

624

625

626

627

628

629

630

631

632

633

634

635

Pennebaker, J. W. (1997). Writing About Emotional Experiences as a Therapeutic Process. Psychological Science, 8, 162-166. https://doi.org/10.1111/j.14679280.1997.tb00403.x

Ryan, R. M., \& Frederick, C. (1997). On energy, personality, and health: Subjective vitality as a dynamic reflection of well-being. Journal of Personality, 65, 529-565. doi:10.1111/j.1467-6494.1997.tb00326.x

Sandal, G. M., \& Smith, N. (2017). Individual resilience. In T. Sgobba, B. Kanki, J-F. Clervoy \& G. M. Sandal (Eds.), Space Safety and Human Performance (pp. 20-30). Cambridge, MA: Butterworth-Heinemann.

Sandal, G. M., Leon, G., \& Palinkas, L. A. (2006). Human challenges in polar and space environments. Environmental Science and Biotechnology, 5, 281-296.

Sandal, G. M., van der Vijver, F., \& Smith, N. (2018). Psychological hibernation during overwintering in Antarctica. Frontiers in Psychology. doi: 10.3389/fpsyg.2018.02235

Sandal, G. M., Endresen, I. M., Vaernes, R., \& Ursin, H. (1999). Personality and coping strategies during submarine missions. Military Psychology, 11, 381-404. doi:10.1207/s 15327876mp1104_3

Sandal, G.M., Bergan, T., Warncke, M., Værnes, R.J. \& Ursin, H. (1996). Psychological reactions during polar expeditions and isolation in hyperbaric chambers. Aviation Space and Environmental Medicine, 67, 227-234

Schreurs, P. J. G., Tellegen, B., Van der Willige, G., \& Brosshot, J. F. (1988). Utrecht Coping List: Handbook. Lisse, Belgium: Swets \& Zeitlinger 
636

637

638

639

640

641

642

643

644

645

646

647

648

649

650

651

652

653

654

655

656

Smith, N. (2018). Relations between self-reported and linguistic monitoring assessments of affective experience in an extreme environment. Wilderness and Environmental Medicine, 29, 61-65. DOI: https://doi.org/10.1016/j.wem.2017.08.023

Smith, N., \& Barrett, E. C. (2018). Psychology, Extreme Environments, and Counterterrorism Operations. Behavioral Sciences of Terrorism and Political Aggression, 11, 48-72. https://doi.org/10.1080/19434472.2018.1551916

Smith, N., Barrett, E. C., \& Sandal, G. M. (2018). Monitoring daily events, coping strategies and emotion during a desert expedition in the Middle East. Stress \& Health, 34, 534544. DOI: doi: 10.1002/smi.2814

Smith, N., Kinnafick, F., \& Saunders, B. (2017). Coping Strategies Used During an Extreme Antarctic Expedition. Journal of Human Performance in Extreme Environments, 13, 110. DOI: $10.7771 / 2327-2937.1078$

Soto, C. J., \& John, O. P. (2009). Ten facet scales for the Big Five Inventory: Convergence with NEO PI-R facets, self-peer agreement, and discriminant validity. Journal of Research in Personality, 43, 84-90. doi:10.1016/j.jrp.2008.10.002

Suedfeld, P. (2001). Applying positive psychology in the study of extreme environments. Journal of Human Performance in Extreme Environments, 6, 21-25. doi:10.7771/23272937.1020

Suedfeld, P. (2012). Extreme and Unusual Environments: Challenges and Responses. In S. D. Clayton (Ed). The Oxford Handbook of Environmental and Conservation Psychology. Oxford Handbooks Online. DOI: 10.1093/oxfordhb/9780199733026.013.0019 
657

658

659

660

661

662

663

664

665

666

667

668

669

670

671

672

673

674

675

676

677

678

Suedfeld, P., Shiozaki, L., Archdekin, B., Sandhu, H., \& Wood, M. (2017). The polar exploration diary of Mark Wood: a thematic content analysis. The Polar Journal, 7, 227-241, DOI: 10.1080/2154896X.2017.1333327

Tice, D. M., Baumeister, R. F., Shmueli, D., \& Muraven, M. (2007). Restoring the self: Positive affect helps improve self-regulation following ego depletion. Journal of Experimental Social Psychology, 43, 379-384. http://dx.doi.org/10.1016/j.jesp.2006.05.007

Suedfeld, P. (2018). Antarctica and space as psychosocial analogues. REACH: Reviews in Human Space Exploration, 9-12, 1-4. https://doi.org/10.1016/j.reach.2018.11.001

Van Dam, N. T., \& Earleywine, M. (2011). Validation of the Center for Epidemiologic Studies Depression Scale_-Revised (CESD-R): Pragmatic depression assessment in the general population. Psychiatry Research, 186, 128-132. https://doi.org/10.1016/j.psychres.2010.08.018

Vansteenkiste, M., \& Ryan, R. M. (2013). On psychological growth and vulnerability: Basic psychological need satisfaction and need frustration as a unifying principle. Journal of Psychotherapy Integration 23, 263-280. http://dx.doi.org/10.1037/a0032359

Wagstaff, C. R. D., \& Leach, J. (2015). The Value of Strengths-Based Approaches in SERE and Sport Psychology. Military Psychology, 27, 65-84. http://dx.doi.org/10.1037/mil0000066

Wagstaff, C. R. D., \& Weston, N. J. V. (2014). Examining Emotion Regulation in an Isolated Performance Team in Antarctica. Sport, Exercise, and Performance Psychology, 3, 237-287. DOI: $10.1037 /$ spy0000022 
679

680

681

682

683

684

685

686

687

688

Watson D, Clark L. A, \& Tellegen A. (1988). Development and Validation of Brief Measures of Positive and Negative Affect: The PANAS scales. Journal of Personality and Social Psychology, 37, 395-412. http://dx.doi.org/10.1037/0022-3514.54.6.1063

Wood, J., Hysong, S. J., Lugg, D. J., \& Harm, D. L. (2000). Is it really so bad? A comparison of positive and negative experiences in Antarctic winter stations. Environment and Behavior, 32, 84-110. https://doi.org/10.1177/00139160021972441

Wood, J., Schmidt, L., Lugg, D., Ayton, J., Phillips, T., \& Shepanek, M. (2005). Life, survival, and behavioral health in small closed communities: 10 years of studying isolated Antarctic groups. Aviation, Space and Environmental Medicine, 76 (S6), B8993. 
689 Table 1

690 Descriptive statistics on pre-departure individual differences

\begin{tabular}{|c|c|c|c|c|c|c|c|}
\hline & Category & Variable & Mean & $\mathrm{SD}$ & Range & Min & Max \\
\hline & Personality & Extraversion & 3.75 & .74 & 2.00 & 2.50 & 4.50 \\
\hline & & Agreeableness & 4.06 & .54 & 1.22 & 3.56 & 4.78 \\
\hline & & Conscientiousness & 4.28 & .49 & 1.44 & 3.44 & 4.89 \\
\hline & & Neuroticism & 1.75 & .52 & 1.50 & 1.00 & 2.50 \\
\hline & & Openness & 3.68 & .43 & 1.20 & 3.20 & 4.40 \\
\hline & Coping Strategies & Active Problem Solving & 3.19 & .41 & 1.00 & 2.57 & 3.57 \\
\hline \multirow[t]{7}{*}{ Pre-expedition } & & Palliative Reactions & 2.29 & .38 & .88 & 1.88 & 2.75 \\
\hline & & Avoidance & 2.00 & .52 & 1.38 & 1.13 & 2.50 \\
\hline & & Social Support & 2.22 & .48 & 1.17 & 1.67 & 2.83 \\
\hline & & Depressive Reactions & 1.33 & .21 & .52 & 1.14 & 1.67 \\
\hline & & Sharing Emotions & 2.11 & .50 & 1.33 & 1.33 & 2.67 \\
\hline & & Comforting Cognitions & 3.27 & .45 & 1.00 & 2.80 & 3.80 \\
\hline & Health \& Wellbeing & Positive Affect & 4.32 & .71 & 1.80 & 3.20 & 5.00 \\
\hline
\end{tabular}


Negative Affect

Wellbeing

Mood (Depression)

691

692

693

694

695

696

697
1.52

5.43

5.33

4.89

.31

.80

1.00

.80

1.29

4.57

5.86

$2.00 \quad .00$

12.00 
698 Table 2

699 Relations between daily markers of physical and psychological health

\begin{tabular}{|c|c|c|c|c|c|c|c|c|c|c|}
\hline & Mean & $\mathrm{SD}$ & Range & Min & Max & Fitness & Exertion & $\begin{array}{l}\text { Positive } \\
\text { Affect }\end{array}$ & $\begin{array}{c}\text { Negative } \\
\text { Affect }\end{array}$ & Stress \\
\hline Fitness & 6.95 & 1.14 & 7.00 & 2.00 & 9.00 & 1 & & & & \\
\hline Exertion & 3.98 & 1.03 & 4.00 & 1.00 & 5.00 & & & & & \\
\hline Positive Affect & 4.03 & 0.69 & 3.30 & 1.70 & 5.00 & & .09 & 1 & & \\
\hline Negative Affect & 1.10 & 0.20 & 1.40 & 1.00 & & & $16 * *$ & $-.50 * *$ & 1 & \\
\hline Stress & 0.88 & 1.34 & 10.00 & 0.00 & 10.00 & $-.26 * *$ & $.15^{*}$ & $-.36 * *$ & $.75^{* *}$ & 1 \\
\hline
\end{tabular}

700

Note: ${ }^{*} \mathrm{p}<.05 ; * * \mathrm{p}<.01$

701

702

703

704

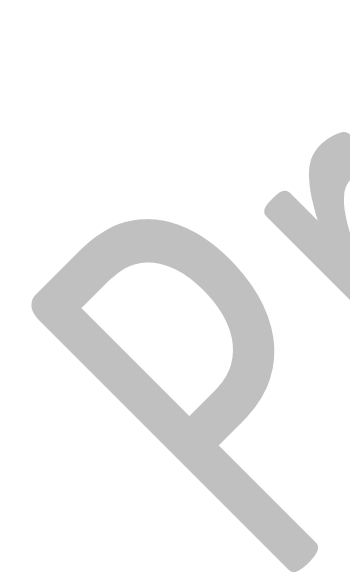


Table 3

Frequency scores and linear mixed models predicting physical and psychological health from daily events reported

\begin{tabular}{|c|c|c|c|c|c|c|c|c|c|c|c|}
\hline \multirow[b]{2}{*}{ Event Reported } & \multirow[b]{2}{*}{$\begin{array}{l}\text { Total } \\
\text { reports }\end{array}$} & \multicolumn{2}{|c|}{ Fitness } & \multicolumn{2}{|c|}{ Exertion } & \multicolumn{2}{|c|}{ Positive Affect } & \multicolumn{2}{|c|}{ Negative Affect } & \multicolumn{2}{|c|}{ Stress } \\
\hline & & Est. & Sig. & Est. & Sig. & Est. & Sig. & Est. & Sig. & Est. & Sig. \\
\hline Able to cope & 230 & $.76^{* *}$ & $<.01$ & -.05 & .72 & $.23 * *$ & .01 & $-.11 * *$ & $<.01$ & $-.99 * *$ & $<.01$ \\
\hline Camaraderie with teammates & 223 & -.14 & .49 & .23 & .21 & -.19 & .07 & .03 & .42 & .20 & .38 \\
\hline Enjoyed the environment & 221 & .20 & .13 & -.03 & .81 & $.27 * *$ & $<.01$ & -.02 & .34 & $-.33 *$ & .02 \\
\hline Satisfied in making good progress & 205 & .16 & .19 & .11 & .33 & $.26 * *$ & $<.01$ & $-.06 * *$ & .01 & -.13 & .34 \\
\hline Muscle and joint pains & 163 & .00 & .99 & $.51 * *$ & $<.01$ & -.04 & .49 & $.05 *$ & .01 & $.33 *$ & .01 \\
\hline Equipment was working & 115 & .02 & .88 & -.12 & .37 & $.15^{*}$ & .04 & -.03 & .21 & $-.35 *$ & .03 \\
\hline Lack of sleep & 102 & -.08 & .59 & $.42 * *$ & $<.01$ & .03 & .70 & .00 & .87 & .08 & .48 \\
\hline Had gear problems & 97 & .00 & .98 & .04 & .72 & .07 & .28 & .00 & .98 & .04 & .77 \\
\hline Feared injury & 75 & $-.32 *$ & .02 & .03 & .79 & $-.14 *$ & .04 & -.03 & .20 & -.14 & .38 \\
\hline Hygiene concerns & 73 & $.61 *$ & .03 & .30 & .22 & .00 & 1.00 & -.05 & .29 & -.11 & .72 \\
\hline Teammate wellbeing concerns & 72 & .18 & .21 & $.40 * *$ & $<.01$ & -.03 & .63 & -.03 & .24 & -.13 & .40 \\
\hline
\end{tabular}




\begin{tabular}{|c|c|c|c|c|c|c|c|c|c|c|c|}
\hline Loneliness & 53 & $-.36^{*}$ & .04 & .18 & .26 & -.10 & .28 & $.10 * *$ & $<.01$ & $.60 * *$ & $<.01$ \\
\hline Worried about bad weather & 50 & .15 & .36 & $-.32 *$ & .02 & .04 & .61 & .01 & .65 & -.24 & .17 \\
\hline Worried about friends or family & 49 & -.39 & .07 & -.24 & .21 & -.08 & .48 & .07 & .07 & -.14 & .56 \\
\hline Lacked privacy & 32 & .00 & .99 & .03 & .86 & .13 & .23 & $-.10 * *$ & .01 & -.39 & .10 \\
\hline Team effectiveness concerns & 31 & $.47 *$ & .03 & -.27 & .15 & -.04 & .74 & -.02 & .68 & -.13 & .58 \\
\hline Headache & 13 & $-.59 *$ & .03 & .06 & .80 & $-.27 *$ & .05 & .05 & .31 & .23 & .43 \\
\hline Tension with teammates & 12 & -.01 & .98 & .38 & .13 & -.15 & .31 & $.12 *$ & .02 & .11 & .35 \\
\hline Worried about safety decisions & 6 & .62 & .11 & .24 & .48 & .36 & .07 & -.02 & .82 & $-.94 *$ & .03 \\
\hline Down/stressed because teammate is & 6 & -.27 & .54 & .30 & .43 & -.18 & .41 & .02 & .77 & .22 & .65 \\
\hline
\end{tabular}

Note: $* \mathrm{p}<.05 ; * * \mathrm{p}<.01$ 
$716 \quad$ Table 4

717 Frequency scores and linear mixed models predicting physical and psychological health from coping strategies used

\begin{tabular}{|c|c|c|c|c|c|c|c|c|c|c|c|}
\hline \multirow[b]{2}{*}{ Coping Strategy } & \multirow[b]{2}{*}{$\begin{array}{l}\text { Total } \\
\text { reports }\end{array}$} & \multicolumn{2}{|c|}{ Fitness } & \multicolumn{2}{|c|}{ Exertion } & \multicolumn{2}{|c|}{ Positive Affect } & \multicolumn{2}{|c|}{ Negative Affect } & \multicolumn{2}{|c|}{ Stress } \\
\hline & & Est. & Sig. & Est. & Sig. & Est. & Sig. & Est. & Sig. & Est. & Sig. \\
\hline Wrote in a journal & 292 & -.30 & .24 & -.19 & .38 & $-.39 * *$ & $<.01$ & .02 & .57 & .17 & .48 \\
\hline Thought about something pleasant & 268 & .23 & .21 & .30 & .06 & $.24 * *$ & .01 & -.02 & .48 & -.25 & .16 \\
\hline Kept the goal in sight & 231 & -.19 & .27 & .24 & .09 & -.15 & .07 & .03 & .23 & .25 & .12 \\
\hline Kept a positive attitude, used humor & 231 & .05 & .14 & .20 & .10 & .06 & .39 & .01 & .61 & .04 & .78 \\
\hline Saw the situation in a positive way & 221 & .12 & .47 & -.01 & .95 & $.30 * *$ & $<.01$ & -.05 & .08 & $-.51 * *$ & $<.01$ \\
\hline Relaxed or meditated & 197 & .32 & .07 & -.18 & .23 & .01 & .95 & $-.09 * *$ & $<.01$ & -.33 & .06 \\
\hline Took it one day at a time & 177 & .18 & .22 & .16 & .22 & -.12 & .10 & .03 & .22 & $.56^{* *}$ & $<.01$ \\
\hline Immersed self in the task & 146 & .10 & .47 & .22 & .06 & .06 & .40 & -.01 & .64 & .05 & .69 \\
\hline Tried harder & 145 & -.22 & .24 & $.39 *$ & .02 & .17 & .06 & -.05 & .09 & -.26 & .18 \\
\hline Kept feelings to self & 115 & -.35 & .09 & -.07 & .59 & -.03 & .65 & .02 & .35 & .09 & .49 \\
\hline Tried to solve problems & 92 & -.10 & .47 & .20 & .08 & -.05 & .41 & .03 & .25 & $.33^{*}$ & .01 \\
\hline
\end{tabular}


Discussed task concerns

\section{Prayer}

Had negative feelings about teammate

Discussed personal concerns

Had negative feelings about myself

Cried

Yelled

Note: $* \mathrm{p}<.05 ; * * \mathrm{p}<.01$

$\begin{array}{ccccccccccc}91 & -.09 & .55 & -.10 & .39 & -.08 & .26 & .05^{*} & .04 & .24 & .09 \\ 72 & -.84 * & .04 & -.48 & .17 & -.73^{* *} & <.01 & .38^{* *} & <.01 & 1.79 * * & <.01 \\ 60 & .26 & .10 & -.05 & .72 & -.05 & .50 & -.01 & .75 & .03 & .84 \\ 31 & -. .39 * & .04 & .13 & .43 & .05 & .58 & .03 & .31 & .13 & .49 \\ 27 & -.35 & .09 & .54 * * & <.01 & -.23 * & .02 & .12 * * & <.01 & .94 * * & <.01 \\ 4 & -.74 & .12 & 1.00^{*} & .01 & -.29 & .22 & .05 & .54 & -.17 & .72 \\ 0 & 0 & . & 0 & . & 0 & . & 0 & . & 0 & .\end{array}$


Table 5

Indicator wave analysis demonstrating change in events and coping strategy use between $1^{\text {st }}$ and $2^{\text {nd }}$ half of expedition

\begin{tabular}{|c|c|c|c|c|c|c|c|}
\hline \multicolumn{3}{|c|}{ Events } & \multicolumn{5}{|c|}{ Coping strategies } \\
\hline & 1 st & 2nd & $\Delta$ & & $1 \mathrm{st}$ & 2 nd & $\Delta$ \\
\hline Able to cope & -.30 & .40 & + & Wrote in a journal & -.60 & .90 & + \\
\hline Camaraderie with teammates & -.30 & .40 & + & Thought about something pleasant & -.20 & .30 & + \\
\hline Enjoyed the environment & -.70 & & & Kept the goal in sight & -1.00 & 1.40 & + \\
\hline Satisfied in making good progress & -.40 & & + & Kept a positive attitude, used humor & -.60 & .80 & + \\
\hline Muscle and joint pains & 1.00 & & & Saw the situation in a positive way & -1.00 & 1.30 & + \\
\hline Equipment was working & .40 & -.60 & P & Relaxed or meditated & -.30 & .40 & + \\
\hline Lack of sleep & & & - & Took it one day at a time & -.90 & 1.20 & + \\
\hline Had gear problems & & 2.50 & + & Immersed self in the task & 1.40 & -1.90 & - \\
\hline Feared injury & & .90 & + & Tried harder & .30 & -.40 & - \\
\hline Hygiene concerns & -.10 & .20 & + & Kept feelings to self & .50 & -.70 & - \\
\hline Teammate wellbeing concerns & 2.50 & -3.50 & - & Tried to solve problems & 1.20 & -1.70 & - \\
\hline
\end{tabular}


Loneliness

Worried about bad weather

Worried about friends or family

Lacked privacy

Team effectiveness concerns

Headache

Tension with teammates

Worried about safety decisions

Down/stressed because teammate is

$\begin{array}{lllllll}-.90 & 1.30 & + & \text { Discussed task concerns } & .20 & -.30 & - \\ -1.10 & 1.50 & + & \text { Prayer } & -.50 & .70 & + \\ 1.20 & -1.60 & - & \text { Had negative feelings about teammate } & .90 & -1.30 & - \\ 1.70 & -2.40 & - & \text { Discussed personal concerns } & .10 & -.30 & - \\ 1.90 & -2.60 & - & \text { Had negative feelings about myself } & .40 & -.50 & - \\ .50 & -.70 & - & \text { Cried } & .20 & -.30 & - \\ .40 & -.60 & - & \text { Yelled } & .00 & .00 & \\ .00 & .00 & & & & & \end{array}$

727 Note: Numeric values are standardized residual scores. + indicates an increase from $1^{\text {st }}$ to $2^{\text {nd }}$ half of expedition and - indicates decrease from $1^{\text {st }}$ 728 to $2^{\text {nd }}$ half of the expedition

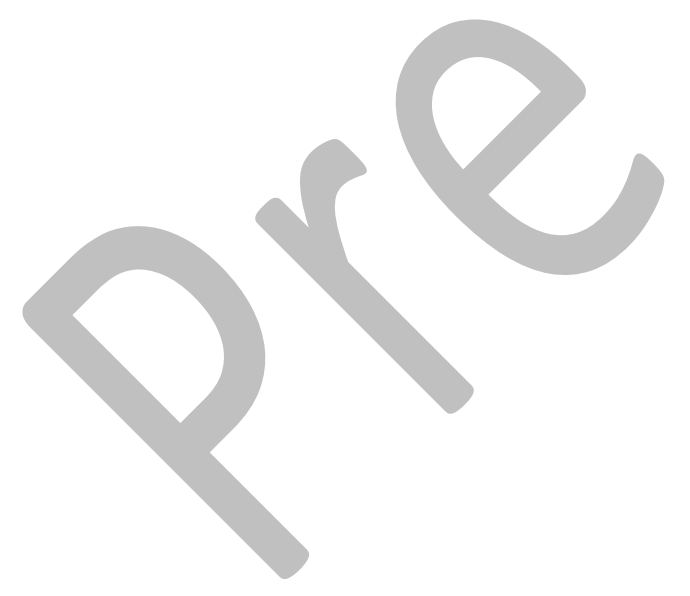

